\title{
Comparative assessment of probiotics and monensin in the prophylaxis of acute ruminal lactic acidosis in sheep
}

\author{
Leonardo Frasson Reis ${ }^{1}$, Rejane Santos Sousa ${ }^{1}$, Francisco Leonardo Costa Oliveira', \\ Frederico Augusto Mazzocca Lopes Rodrigues ${ }^{1}$, Carolina Akiko Sato Cabral Araújo', \\ Enoch Brandão Souza Meira-Júnior ${ }^{1}$, Raimundo Alves Barrêto-Júnior ${ }^{2}$, Clara Satsuki Mori ${ }^{1}$, \\ Antonio Humberto Hamad Minervino ${ }^{3}$ and Enrico Lippi Ortolani ${ }^{*}$
}

\begin{abstract}
Background: Acute ruminal lactic acidosis (ARLA) is a major nutritional and metabolic disorder usually characterized by excessive or non-adapted intake of diets rich in nonstructural carbohydrates. Feed additives that regulate the ruminal environment have been used to prevent ARLA, such as ionophores and, more recently, yeast culture. Thus, we aimed to compare the efficacy of a yeast-based culture (Saccharomyces cerevisiae) with that of monensin sodium in the prevention of ARLA in sheep. Eighteen male, crossbred, rumen-cannulated sheep were randomly distributed into three groups of six animals: control, yeast culture and monensin. Thirty days after the start of supplementation with yeast culture ( $4 \times 10^{9} \mathrm{cfu} / \mathrm{animal} /$ day of S. cerevisiae) and monensin (33 mg/kg of total dry matter intake), $15 \mathrm{~g} / \mathrm{kg} \mathrm{BW}$ of sucrose was administered directly into the rumen of the animals to induce ARLA. Samples of blood and ruminal fluid were collected at the following time points: at baseline (TO $h$ ) immediately before the induction of ARLA; $6 \mathrm{~h}(T 6 \mathrm{~h})$; $12 \mathrm{~h} \mathrm{(T12} \mathrm{h);} 18$ h (T18 h); 24 h (T24 h); 36 h (T36 h); and 48 h (T48 h) after ARLA induction.

Results: Ruminal $\mathrm{pH}$ was higher in monensin group at $\mathrm{T} 12 \mathrm{~h}$ and in yeast culture group at $\mathrm{T} 36 \mathrm{~h}$ when compared to control group. Lower values of L-Lactate were found at yeast culture group at T24 $\mathrm{h}$ and T36 h. Monensin showed prophylactic effect by decreasing the rate of ruminal pH decline and occasionally reducing ruminal acidosis, whereas probiotics resulted in less accumulation of lactic acid in the rumen and a lower degree of systemic acidosis.

Conclusion: The use of yeast culture can be beneficial in the prevention and treatment of ARLA in sheep, because it can effectively reduce the accumulation of lactic acid, and thereby increase ruminal $\mathrm{pH}$ and reduce ruminal osmolarity. On the other hand, monensin showed prophylactic effect by decreasing the rate of ruminal $\mathrm{pH}$ decline and occasionally reducing ruminal acidosis, however, it did not directly prevent these conditions.
\end{abstract}

Keywords: Prevention, Additives, lonophores, Ruminal pH

\footnotetext{
* Correspondence: ortolani@usp.br; enrico.ortolani@pq.cnpq.br

${ }^{1}$ Department of Clinical Science, Faculty of Veterinary Medicine and Animal

Science, University of São Paulo, Av. Prof. Orlando Marques de Paiva, 87,

Cidade Universitária, CEP, São Paulo, SP 05508-270, Brazil

Full list of author information is available at the end of the article
}

(c) The Author(s). 2018 Open Access This article is distributed under the terms of the Creative Commons Attribution 4.0 International License (http://creativecommons.org/licenses/by/4.0/), which permits unrestricted use, distribution, and reproduction in any medium, provided you give appropriate credit to the original author(s) and the source, provide a link to the Creative Commons license, and indicate if changes were made. The Creative Commons Public Domain Dedication waiver (http://creativecommons.org/publicdomain/zero/1.0/) applies to the data made available in this article, unless otherwise stated. 


\section{Background}

Sheep use complex carbohydrates (structural and nonstructural) as their main source of energy, and require these nutrients in the diet to maintain healthy, stable ruminal conditions [1]. Nevertheless, feeding practices that use nonstructural carbohydrates aimed at achieving high levels of productivity, have led to increased levels of fermentation and the production of organic acids, and a subsequent reduction of ruminal $\mathrm{pH}$ [2]. Although increased acid production can sometimes be desirable, this type of nutritional management can challenge the equilibrium of the ruminal ecosystem and compromise animal health [3].

Acute ruminal lactic acidosis (ARLA) is a major nutritional and metabolic disorder usually characterized by excessive or non-adapted intake of diets rich in nonstructural carbohydrate. The excessive ingestion of nonstructural carbohydrates, rich in sugar, starch and pectin, causes sudden, exponential growth of specific Gram-positive bacteria (Streptococcus bovis and Lactobacillus sp) that generate intense production of lactic acid and cause a sharp drop in ruminal $\mathrm{pH}$, which then interferes with the activity and survival of lactate-utilizing (Gram-negative) bacteria that transform lactic acid into inactive substances $[4,5]$.

It is therefore necessary to use tools that maximize the potential for production, by facilitating small adjustments to the process of ruminal fermentation, while using diets rich in nonstructural carbohydrates [6]. In this context, feed additives have been used to prevent ARLA, such as ionophores and yeast culture that regulate the ruminal environment to increase feed efficiency $[7,8]$.

Ionophores are antimicrobial compounds produced by various strains of Streptomyces sp. that have a selective inhibitory action on Gram-positive bacteria and allow the survival of Gram-negative bacteria. Monensin sodium is the most commonly used ionophore in the prevention of ARLA in beef cattle [9]. Nevertheless, monensin is not approved for use in ruminants in all countries $[10,11]$.

Yeast culture are additives composed of live microorganisms that improve animal productivity and promote the growth of bacteria (particularly cellulolytic and lactate-utilizing bacteria) and protozoa in the rumen [4], thus, it could be used in substitution of ionophores in ruminants.

Although Saccharomyces cerevisiae has been tested in several in vitro and in vivo trials to increase the activity of lactate-utilizing bacteria [12-16], to our knowledge, no study has been conducted to assess the preventive effects of probiotics in ARLA under controlled experimental conditions, particularly in sheep. Moreover, to our knowledge, there are no studies that compare the action of these yeast culture with that of monensin sodium in the prophylaxis and treatment of ARLA in sheep.

Therefore, the present study aimed to compare the effects of a yeast culture that contains Saccharomyces cerevisiae with those of monensin sodium on ruminal and hematological variables and assess the efficacy of both additives in the prevention and treatment of sheep affected by ARLA.

\section{Methods}

The sheep used in the experiment were purchased at properties near the city of São Paulo, obeying the norms of acquisition of animals for experimentation and with the aproval of the Ethics Committee on Animal Research of the Faculty of Veterinary Medicine and Animal Science, University of São Paulo (Protocol no. 1587/ 2009).

\section{Animals and diet}

Eighteen male 24-month-old, Santa Inês crossbred sheep with a mean body weight of $45 \pm 1.2 \mathrm{~kg}$ were used. Sixty days before the start of the study, all animals were treated with a moxidectin-based endectocide (Cydectin, Zoetis Animal Health, São Paulo, Brazil) and were surgically fitted with a ruminal silicone cannula. The animals were subsequently allowed to recover and adapt to the feeding protocol.

During the adaptation period and throughout the study, the sheep were fed a basal diet calculated at $2.7 \%$ body weight, dry matter (DM) basis, with $75 \%$ being coast-cross grass (Cynodon dactylon) and 25\% commercial concentrate with 14\% crude protein (Fri-Sheep 22/ 70, Nutreco Nutrição Animal, Pitangueiras, Brazil). The hay and concentrate were mixed and the diet was offered at once in the morning. The animals had free access to mineral salt (Ovinofós, Tortuga, São Paulo, Brazil) and water. The sheep were weighed every week and the diet was correct accordingly.

\section{Study design}

The experimental design was completely randomized with distribution of the 18 sheep into three groups of six animals: the control, yeast culture, and monensin groups. The control group received the basal diet; the yeast culture group received the basal diet and $5 \mathrm{~g}$ of yeast culture/animal/day (Yea-Sacc 1026, Alltech SA, Araucária, Brazil) that resulted in a total inoculation of $4 \times 10^{9} \mathrm{cfu} /$ animal/day of Saccharomyces cerevisiae strain 1026; and the monensin group received $33 \mathrm{mg}$ of monensin sodium (Rumensin, Elanco, São Paulo, Brazil) per $\mathrm{kg}$ of diet [17], i.e. a sheep weighing $45 \mathrm{~kg}$ BW received daily $1.215 \mathrm{~kg}$ of diet (DM) and $40.1 \mathrm{mg}$ of sodium monensin. Yeast culture and monensin were both administered directly into the rumen via the ruminal 
cannula immediately after the animals were fed. Monensin dose were adjusted weekly according the diet.

Ruminal lactic acidosis was experimentally induced, 30 days after the additives were introduced. The experimental model entailed the administration of sucrose into the rumen [18], according to the modifications recommended by Afonso et al. [17] for sheep. For this purpose, $15 \mathrm{~g}$ of sucrose per $\mathrm{kg}$ of body weight was administered directly into the rumen.

Blood and ruminal fluid samples were collected at the following time points: at baseline ( $\mathrm{T} 0 \mathrm{~h}$ ) immediately before the induction of ARLA, and at 6 (T6 h), 12 (T12 h),

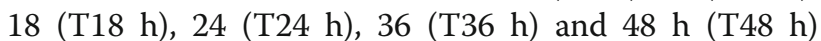
after induction of ARLA. Starting at T24 h until T48 h, fresh grass was offered to each animal to evaluate the presence or absence of appetite.

To protect the welfare of the animals, all sheep that exhibited clinical signs of systemic acidosis and had blood $\mathrm{pH} \leq 7.2$ were treated at $\mathrm{T} 24 \mathrm{~h}$. Treatment consist of intravenous infusion of isotonic saline solution $(20 \mathrm{~mL} / \mathrm{kg} \mathrm{BW})$ and isotonic sodium bicarbonate (1.3\%), according to the classic formula of buffer replacement [19]. In addition, at T24 $\mathrm{h}$, the control group received $5 \mathrm{~g}$ of sodium chloride into the rumen, and the monensin and yeast culture groups received the respective additives at the aforementioned doses.

\section{Ruminal content samples}

Aliquots of ruminal contents were collected at the specified time points using a probe placed in the ventral sac of the rumen and a vacuum pump. Approximately $100 \mathrm{~mL}$ of fluid was collected, filtered with gauze, and frozen at $-20{ }^{\circ} \mathrm{C}$ for subsequent determination of osmolarity and concentration of L-lactate.

\section{Ruminal evaluation by the continuous telemetry system} During the induction of ARLA, rumen $\mathrm{pH}$ and temperature were measured continuously by a telemetric system of data acquisition using a device composed of a submersible electrode (model PHE-6510), a data logger (model OM-CP-PH10), an interface cable (model OM-CP-IFC110) and the Omega 2.04.6 software (Omega Engineering Inc., Campinas, Brazil), according to the recommendations of Alzahal et al. [20]. The electrode was placed in the animals at $\mathrm{T} 0 \mathrm{~h}$ and remained within the ventral sac of the rumen for 48 consecutive hours. Ruminal temperature and $\mathrm{pH}$ were recorded every $5 \mathrm{~min}$ (with sensitivities of $0.01{ }^{\circ} \mathrm{C}$ and 0.01 , respectively).

\section{Blood samples}

Arterial blood samples were collected from auricular artery at all time points using a scalp (23G) coupled to heparinized syringes. Blood gas was performed in an automated analyzer (Cobas 212, Roche Diagnostics,
Basel, Switzerland). The following parameters were evaluated: blood $\mathrm{pH}$, concentration of bicarbonate, and base excess (BE). The results were corrected according to the rectal temperature of the animal $[21,22]$.

Plasma samples were collected in tubes containing sodium fluoride to determine L-lactate and glucose concentrations, whereas serum samples were used to determine serum osmolarity.

\section{Laboratory analysis}

The levels of plasma and ruminal L-lactate and plasma glucose were measured using commercial kits (Randox, Antrium, UK) in an automated biochemistry analyzer (RX Daytona, Randox, Antrium, UK). Determination of serum and ruminal osmolarities were based on the freezing point method and conducted in an osmometer (Advanced Micro-Osmometer 3300, Advanced $^{\mathrm{m} \mathrm{T}}$ Instruments, Norwood, USA).

The methylene blue reduction test was performed in the ruminal fluid at $\mathrm{T} 36 \mathrm{~h}$ and $\mathrm{T} 48 \mathrm{~h}$ using the classic technique described by Dirksen et al. [23].

\section{Statistical analysis}

Statistical analysis was performed using the SAS 9.3 statistical software. The tests of normality of residuals and homogeneity of variance were performed, the variables that met the assumptions were subjected to analysis of variance using the PROC MIXED procedure for measurements repeated over time. For each variable, the effect of treatment, time and interaction between treatment and time was analysed. It was considered the Akaike Information Criterion (AIC) for choosing the best covariance structure. In the evaluation of rumen osmolarity, T0 h values were used as covariate since the presented statistical difference between groups. Comparisons between the means of groups at each interval (P) were performed using the least square means (LS Means) test. Correlation coefficients were calculated and regression equations were derived to determine the relationship between two variables. The level of significance was set at $5 \%$.

\section{Results}

Values of $\mathrm{pH}$, temperature, osmolarity and concentration of L-lactic in the ruminal content recorded throughout the study are presented in Table 1. Animals of the probiotic group had higher ruminal $\mathrm{pH}$ values $($ Trat $=0.01$; Time $=0.01 ;$ Trat*Time $=0.14)$ when compared to the control and monensin groups. At $\mathrm{T} 12 \mathrm{~h}$, the $\mathrm{pH}$ of ruminal contents in the monensin group was higher than that in the control group, but identical to that in the yeast culture group. On the other hand, at T36 h and $\mathrm{T} 48 \mathrm{~h}$, the $\mathrm{pH}$ of ruminal contents in the yeast culture group was significantly higher than that in the control 


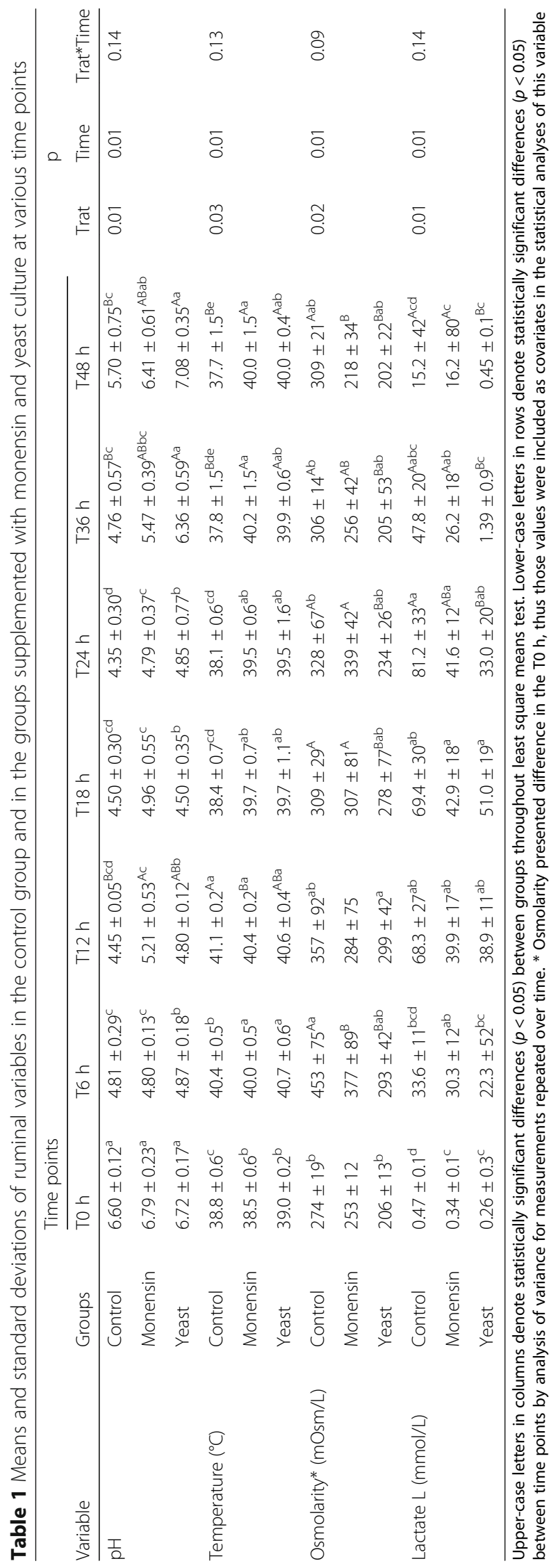


group and identical to that in the monensin group. There were significant differences in intraruminal temperature among the groups at three time points, whereas the animals of the monensin and probiotic groups presented higher values (Trat $=0.03$, Time $=0.01$, Trat*Time $=0.13$ ). At $\mathrm{T} 12 \mathrm{~h}$, the ruminal temperature of the control group was higher than that of the other groups, whereas at $\mathrm{T} 36 \mathrm{~h}$ and $\mathrm{T} 48 \mathrm{~h}$, the ruminal temperature of the yeast culture and monensin groups was higher than that of the control group.

At baseline ( $\mathrm{T} 0 \mathrm{~h}$ ) the probiotic group presented lower values of ruminal osmolarity and this time point became a covariate in the analyses. The highest values of ruminal osmolarity were observed at T6 h among all groups and at this time point, the control group exhibited higher values of ruminal osmolarity than the other groups (Trat $=0.02$; Time $=0.01$; Trat*Time $=0.09$ ). At the time points T18 h and T24 h the osmolarity in those animals that received yeast culture supplementation was lower than that in the control and monensin groups; and there was no significant difference between the two latter groups. However, at T48 h, osmolarity in the monensin and yeast culture groups was lower than that in the control group.

Lower concentrations of rumen lactate were detected in the animals of the probiotic group when compared to the monensin and control groups (Trat $=0.01$; Time $=0.01$; Trat ${ }^{*}$ Time $\left.=0.14\right)$. From T6 h onwards, there was an increase in the concentration of L-lactic acid in the ruminal contents of all groups, with maximum values being observed at $\mathrm{T} 18 \mathrm{~h}$ in the yeast culture and monensin groups, and at T24 h in the control group. Between $\mathrm{T} 24 \mathrm{~h}$ and $\mathrm{T} 48 \mathrm{~h}, \mathrm{~L}-$ lactate levels were higher in the control group than in the yeast culture group. At $\mathrm{T} 48 \mathrm{~h}$, the mean concentration of L-lactate in the ruminal contents of the yeast culture group was similar to that of the baseline value, an observation that was not evident in the other groups.

The results of the methylene blue reduction test were lower $(p=0.040)$ in the yeast culture group at T36 h and T48 $\mathrm{h}$ (5 $\mathrm{min}$ and $<3 \mathrm{~min}$, respectively) than those in the monensin group (30 $\mathrm{min}$ and $10 \mathrm{~min}$, respectively), and in the control group (40 $\mathrm{min}$ and $15 \mathrm{~min}$, respectively); however, these differences were not statistically significant.

Figure 1 shows the results of the analyzed blood variables. From T12 h onwards, all groups had blood $\mathrm{pH}$ values below baseline values (T0 h). The values of blood $\mathrm{pH}$ from the yeast group were higher than control and monensin groups (Trat $=0.03$; Time $=0.04$; Trat*Time $=0.32)$. The base excess was lower in the yeast culture group $\left(\right.$ Trat $=0.04 ;$ Time $=0.02$; Trat $^{*}$ Time $=0.28$ ) than other groups, whereas the concentration of bicarbonate was lower in the control and monensin groups than it was in the yeast culture group (Trat $=0.03$; Time $=0.01$; Trat*Time $=0.38$ ).

There were not significant differences in plasma Llactate concentration among the groups (Trat $=0.34$; Time $=0.01 ; \quad$ Trat ${ }^{*}$ Time $\left.=0.53\right)$. The comparison between time points showed that there were significant differences only within the control group, namely a significant increase at $\mathrm{T} 6 \mathrm{~h}$ (the time point at which the concentration of L-lactate reached its maximum in the control group).

Serum osmolarity in the control group was higher than that in the yeast culture group (Trat $=0.04$; Time $=0.01$; Trat*Time $=0.15)$. At T6 $\mathrm{h}$ and $\mathrm{T} 12 \mathrm{~h}$ yeast culture group exhibiting the lowest osmolarity values of the three groups. In addition, serum osmolarity of the yeast culture group was significantly different from that of the control group, but showed no significant difference from that of the monensin group. At $\mathrm{T} 48 \mathrm{~h}$, the concentration of plasma glucose was highest in the control group and there were no significant differences between the monensin and yeast culture groups, but no treatment effect was detected for this variable among the studied groups (Trat $=0.23$; Time $=0.02$; Trat ${ }^{*}$ Time $=0.43$ ).

Three animals from the control group and two from the monensin group required treatment at T24 h. This animals exhibited absence of appetite at T24 h. Only one animal (from control group) had severe acidosis, with a blood $\mathrm{pH}$ of 7.07 . At $\mathrm{T} 36 \mathrm{~h}$, all treated animals had increased blood $\mathrm{pH}$. No animals in the probiotic group required support treatment.

\section{Discussion}

The methods of the present study effectively induced ARLA, achieving significant ruminal $\mathrm{pH}$ values, specifically a mean of 4.0 at $\mathrm{T} 24 \mathrm{~h}$ in the control group, which indicates severe ruminal acidosis [19]. The results observed in the control group suggest that the amount of substrate used facilitated continuous fermentation of sucrose up to $\mathrm{T} 24 \mathrm{~h}$, with decrease in ruminal $\mathrm{pH}$ and accumulation of lactic acid in the rumen.

The results of ruminal $\mathrm{pH}$ showed that monensin had a positive effect at T12 h by preventing a sharp decline in $\mathrm{pH}$. This possibly occurs due a reduced production of L-lactate and short-chain fatty acid (SCFA), since monensin modulates the activity of lactic acid bacteria that produce SCFAs [9]. At T12 h, the yeast culture had an intermediate effect, probably stimulating the activity of lactic acid consuming bacteria, but exerting less pronounced effects on SCFAproducing bacteria [24].

However, at $\mathrm{T} 24 \mathrm{~h}$, when the concentrations of acids reached maximum values, the yeast culture indirectly promoted a trend of increasing ruminal $\mathrm{pH}$ through a significant reduction in the production of L-lactic acid. 


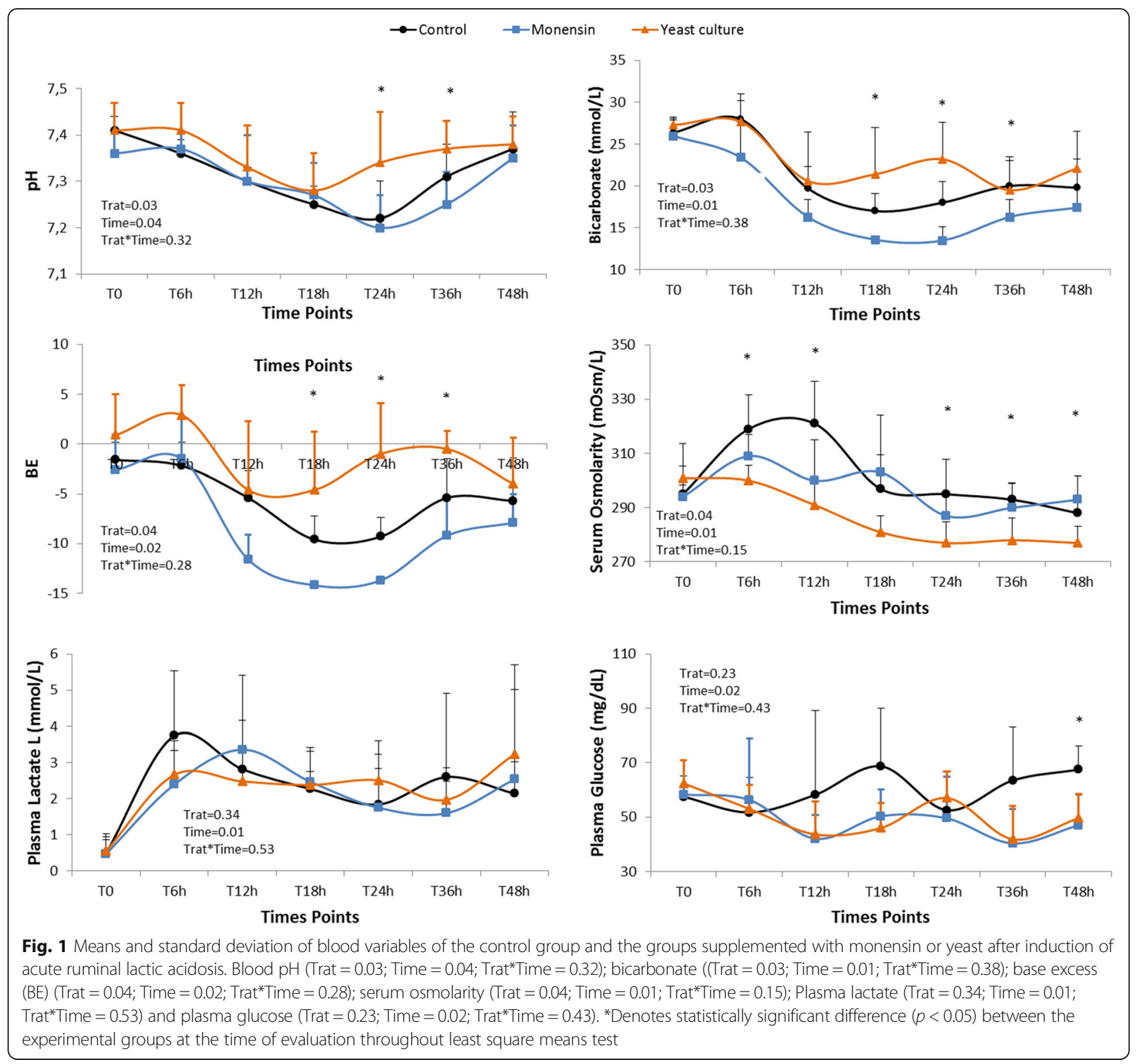

This effect was probably due to competition between the Saccharomyces cerevisiae yeast and the fermenting bacteria that produce lactic acid (particularly Lactobacillus $s p$.) [25], or competition between the Saccharomyces cerevisiae yeast and the substrates made available by the yeast for the growth of those bacteria [24]. The yeast culture exerted its greatest effects between T24 h and T48 h, during recovery from ruminal acidosis. During this period, reductions in the concentration of L-lactic acid in the rumen were significant in the yeast culture group. According to Callaway and Martin [25], probiotic yeasts have a symbiotic relationship with lactic acid consuming bacteria (Selenomonas ruminantium, Megasphaera elsdenii); suggesting that yeasts provide B- complex vitamins and amino acids that stimulate the growth of these bacteria, which utilize the ruminal lactate for metabolism. This effect seemed to be greater after $\mathrm{T} 18 \mathrm{~h}$, when the mean ruminal $\mathrm{pH}$ reached a value of 4.5 , which is the ideal $\mathrm{pH}$ for the multiplication of yeasts [25]. The reduction in the concentration of Llactic acid and the increase in ruminal $\mathrm{pH}$ suggests that the use of yeast culture could be used as ancillary treatment in sheep with ARLA.

Variations in ruminal temperature have been considered only recently, mainly because temperature data is difficult to obtain. According to Alzahal et al. [26], ruminal temperature can be useful in the diagnosis of ruminal acidosis by volatile fatty acids (subacute acidosis). They 
assert that under these ruminal conditions $(\mathrm{pH}$ between 5.6 and 5.0), ruminal temperature increases beyond $39.2^{\circ}$ $\mathrm{C}$, reaching up to $41{ }^{\circ} \mathrm{C}$, and correlates negatively with $\mathrm{pH}$ $(r=-0.87)$. In the present study, ruminal temperature caused by ARLA was measured, at $\mathrm{pH}<5.0$, and a quadratic relationship between $\mathrm{pH}$ and temperature $(r=0.71)$ was observed. At the peak of fermentation (T18 h), when the $\mathrm{pH}$ was approximately 4.2 , ruminal temperature was also at its maximum $\left(40.5^{\circ} \mathrm{C}\right)$, which suggesting an intrinsic relationship between these two variables. At $\mathrm{T} 12 \mathrm{~h}$, the mean temperature in the group supplemented with monensin was lower than that in the control group, which supports the hypothesis that this additive reduces ruminal fermentation at this time point.

However, at $\mathrm{T} 24 \mathrm{~h}$, when ruminal $\mathrm{pH}$ was still very low, there was a drop in ruminal temperature. This probably occurred because the infused substrate, sucrose, had already been completely consumed, reducing ruminal activity, especially in the control group. The mean ruminal temperatures at $\mathrm{T} 36 \mathrm{~h}$ and $\mathrm{T} 48 \mathrm{~h}$ in the control group were lower than those in the monensin and probiotic groups, which suggest that there was a biochemical disruption of ruminal flora in the control group.

At $\mathrm{T} 36 \mathrm{~h}$ and $\mathrm{T} 48 \mathrm{~h}$, the reaction time of the methylene blue reduction test on rumen fluid was shorter in the yeast culture group than in the other groups. In addition, no animal in the yeast culture group exhibited absence of appetite, whereas $50 \%$ of the animals in the control group and $33 \%$ in the monensin group exhibited this condition. One possible hypothesis to explain those finding is that the consumption of oxygen by $S$. cerevisiae favors a return to the normal status (anaerobiosis in particular) of the ruminal environment [27].

As expected, the concentration of ruminal L-lactate significantly affected ruminal osmolarity $(r=0.72)$. Osmolarity in the yeast culture group was lower than that in the control group at T0 h, T24 h, T36 h, and $\mathrm{T} 48 \mathrm{~h}$; the low baseline values observed in the group supplemented with yeast culture are noteworthy. The reason for this difference is unknown and further studies are necessary to interpret these results.

ARLA caused mild to moderate systemic acidosis in most animals, with the exception of one sheep in the control group whose blood pH at T24 h was 7.07 (acute systemic acidosis). Treatment with sodium bicarbonate buffer partially corrected metabolic acidosis in the control and monensin groups at T36 h, because a residual amount of ruminal lactic acid prevented full adjustment of the systemic $\mathrm{pH}$. Moreover, the levels of bicarbonate and base excess in the animals that received yeast culture were higher between T24 h and T36 h, which coincided with the lowest levels of ruminal L-lactic acid in this group.
A trend of increasing concentration of plasma L-lactate over time was observed in the control group. The plasma lactate probably originated from the rumen, because the coefficient of determination between these variables was 0.77. Ruminal L-lactate may led to an increase in the concentration of plasma glucose, especially in the control group, as evidenced by a quadratic relationship $\left(r^{2}=0.54\right)$ between these two variables.

\section{Conclusion}

The use of yeast culture can be beneficial in the prevention and treatment of ARLA in sheep, because it can effectively reduce the accumulation of lactic acid, and thereby increase ruminal $\mathrm{pH}$ and reduce ruminal osmolarity. On the other hand, monensin showed prophylactic effect by decreasing the rate of ruminal $\mathrm{pH}$ decline and occasionally reducing ruminal acidosis, however, it did not directly prevent these conditions.

\section{Abbreviations}

ALRA: ruminal lactic acidosis; SCFA: short-chain fatty acid

\section{Acknowledgements}

The author are grateful to Agnaildo Santos for assistance in animal handle. AHHM is greatfull to Conselho Nacional de Desenvolvimento Científico e Tecnológico for research productivity fellowship.

\section{Funding}

Financial support for this study was provided by the Fundação de Amparo à Pesquisa do Estado de São Paulo (FAPESP).

\section{Availability of data and materials}

The data set supporting the results of this article are available from the corresponding author.

\section{Authors' contributions}

Conceived and designed experiments: ELO, RABJ, AHHM. Preformed cannula implantation surgery: RABJ, AHHM, LFR. Performed the experiments: LFR, RSS, EBSMJ, FLCO, FAMLR, CASCA, CSM. Performed laboratorial analysis: CSM, FLCO, FAMLR, EBSMJ, LFR. Analyzed the data: LFR, RSS, AHHM. Wrote and reviewed the paper: ELO, RABJ, AHHM, LFR, RSS, CASCA, CSM, FAMLR, LFR, FLCO. All authors read and approved the final version of the manuscript.

\section{Ethics approval}

All procedures and animal handling followed the ethical principles in animal experimentation and were previously approved by the Ethics Committee on Animal Research of the Faculty of Veterinary Medicine and Animal Science, University of São Paulo (Protocol \# 1587/2009).

\section{Consent for publication}

Not applicable.

\section{Competing interests}

The authors declare that they have no competing interests.

\section{Publisher's Note}

Springer Nature remains neutral with regard to jurisdictional claims in published maps and institutional affiliations.

\section{Author details}

${ }^{1}$ Department of Clinical Science, Faculty of Veterinary Medicine and Animal Science, University of São Paulo, Av. Prof. Orlando Marques de Paiva, 87, Cidade Universitária, CEP, São Paulo, SP 05508-270, Brazil. Department of 
Animal Science, Federal Rural University of the Semiarid Region, Av. Francisco Mota, s/n - Bairro Pres. Costa e Silva, CEP, Mossoró, RN 59625-900, Brazil. ${ }^{3}$ Laboratório de Sanidade Animal, Universidade Federal do Oeste do Pará (LARSANA/UFOPA), Av. Vera Paz S/N, Salé, CEP, Santarém, PA 68000-000, Brazil.

Received: 16 December 2015 Accepted: 9 November 2017

Published online: 09 January 2018

\section{References}

1. Allen MS. Relationship between fermentation acid production in the rumen and the requirement for physically effective fiber. J Dairy Sci. 1997;80(7):1447-62.

2. Penner GB, Guan LL, Oba M. Effects of feeding Fermenten on ruminal fermentation in lactating Holstein cows fed two dietary sugar concentrations. J Dairy Sci. 2009;92(4):1725-33. PMID: 19307654

3. Aschenbach JR, GBF P, Stumpff F, Gäbel G. Role of fermentation acid absorption in the regulation of ruminal pH. J Anim Sci. 89(4):1092-107.

4. Nagaraja TG, Lechtenberg KF. Acidosis in feedlot cattle. Vet Clin North Am Food Anim Pract. 2007;23(2):333-50.

5. Barrêto Júnior RA, AHH M, FAML R, Antonelli AC, MCA S, Mori CS, Ortolani EL. Avaliação do potencial da polpa cítrica em provocar acidose láctica ruminal aguda em bovinos. Braz J Vet Res Anim Sci. 2008;45(6):421-8.

6. Nagaraja TG. Response of the gut and microbial populations to feedstuffs: the ruminant story. In: Proceedings of the 64th Minnesota nutrition conference. St. Paul, MN, 64-77; 2003.

7. Nagaraja TG, Taylor MB. Susceptibility and resistance of ruminal bacteria to antimicrobial feed additives. Appl Environ Microbiol. 1987;53(7):1620-5.

8. Angeles SCC, Mendoza GDM, Cobos MAP, Crosby MMG, Castrejón FAP. Comparison of two commercial yeast cultures (Saccharomyces cerevisiae) on ruminal fermentation and digestion in sheep fed on corn-stover diet. Small Rumin Res. 1998;31(1):45-50.

9. Nagaraja TG, Avery TB, Bartley EE, Roof SK, Dayton AD. Effect of lasalocid, monensin or thiopeptin on lactic acidosis in cattle. J Anim Sci. 1992;54(3):649-58.

10. Marshall BM, Levy SB. Food animals and antimicrobials: impacts on human health. Clin Microbiol Rev. 2011;24:718-33.

11. REGULATION 1831/2003/EC on additives for use in animal nutrition, replacing Directive 70/524/EEC on additives in feeding-stuffs (2009). http:// eur-lex.europa.eu/eli/reg/2003/1831/2009-06-02. Accessed 20 Aug 2017.

12. Andrighetto I, Bailoni G, Cozzi G, Berzaghi P. Effects of yeast culture addition on digestion in sheep fed a high concentrate diet. Small Rumin Res. 1993; 12(1):27-34.

13. Martin SA, Streeter MN. Effect of malate on in vitro mixed ruminal microorganism fermentation. J An Sci. 1995;73(7):2141-5.

14. Corona L, Mendoza GD, Castrejón FA, Crosby MM, Cobos MA. Evaluation of two yeast cultures (Saccharomyces cerevisiae) on ruminal fermentation and digestion in sheep fed a corn stover diet. Small Rumin Res. 1999;31(3):209-14.

15. Arcos-García JL, Castrejón FA, Mendoza GD, Pérez-Gavilán EP. Effect of two commercial yeast cultures with Saccharomyces cerevisiae on ruminal fermentation and digestion in sheep fed sugar cane tops. Livest Prod Sci. 2000;63(2):153-7.

16. Rossi F, Di Luccia A, Vincenti D, Cocconcelli PS. Effects of peptidic fractions from Saccharomyces cerevisiae culture on growth and metabolism of the ruminal bacteria Megasphaera elsdenii. Anim Res. 2004;53(3):177-86.

17. Afonso JA, Ciarlini PC, Kuchembuck MRG, Kohayagawa A, Feltrin LPZ, LDRP C, Laposy CB, Mendonça CL, Takahira RK. Metabolismo oxidativo dos neutrófilos de ovinos tratados com monensina sódica e experimentalmente submetidos à acidose ruminal. Pesq Vet Bras. 2002;22(4):129-34.

18. Ortolani EL. Induction of lactic acidosis in cattle with sucrose: relationship between dose, rumen fluid $\mathrm{pH}$ and animal size. Vet Human Toxicol. 1995;37(5):462-4

19. Radostits OM, Gay CC, Hinchcliff KW, Constable PD. Veterinary medicine. 10th ed. London: Elsevier Saunders; 2007. 2156 p.

20. Alzahal O, Rustorno B, Odongo NE, Duffield TF, McBride BW. A system for continuous recording of ruminal $\mathrm{pH}$ in cattle. J An Sci. 2007:85(1):213-7.

21. Sucupira MCA, Ortolani EL. Uso de sangue arterial e venoso no exame do equilíbrio ácido-básico de novilhos normais ou com acidose metabólica. Cienc Rural. 2003;33(5):863-8.

22. Dirksen G, Gründer HD, Stöber M. Rosenberger exame clínico dos bovinos. 3rd ed. Rio de Janeiro: Guanabara Koogan; 1993. 419 p.
23. Panchal CJ, Whitney GK, Stewart GG. Susceptibility of Saccharomyces spp. and Schwanniomyces spp. to the aminoglycoside antibiotic G418. App Environ Microbiol. 1984;47(5):1164-6.

24. Hungate RE. The rumen and its microbes. New York: Academic Press; 1966.

25. Callaway ES, Martin SA. Effects of a Saccharomyces cerevisiae culture on ruminal bacteria that utilize lactate and digest cellulose. J Dairy Sci. 1997;80(9):2035-44

26. Alzahal O, Kebreab E, France J, Froetschel M, McBride BW. Ruminal temperature may aid in the detection of subacute ruminal acidosis. J Dairy Sci. 2008;91(1):202-7.

27. Lund A. Yeasts and moulds in the bovine rumen. J Gen Microbiol. 1974; 81(2):453-62.

\section{Submit your next manuscript to BioMed Central and we will help you at every step:}

- We accept pre-submission inquiries

- Our selector tool helps you to find the most relevant journal

- We provide round the clock customer support

- Convenient online submission

- Thorough peer review

- Inclusion in PubMed and all major indexing services

- Maximum visibility for your research

Submit your manuscript at www.biomedcentral.com/submit
Biomed Central 